\title{
Experimental results on an energy pile within a sheet pile wall in Napoli
}

\author{
Marianna Adinolfi ${ }^{1 *}$, Rosa Maria Stefania Maiorano ${ }^{2}$ and Stefano Aversa ${ }^{2}$ \\ ${ }^{1}$ REgional Model and geo-Hydrological Impacts, Centro Euro-Mediterraneo sui Cambiamenti Climatici, 81100, Caserta, Italy \\ ${ }^{2}$ Department of Engineering, University of Napoli Parthenope, 80143 Naples, Italy
}

\begin{abstract}
Energy geo-structures are renewable energy solutions with a double role of structural support and heat exchangers. Some installations are recorded worldwide, but only limited information is available regarding the impact of thermal processes on the structural and geotechnical performance of energy geostructures. A proper experimental campaign was conducted within the underground railway construction site of Piazza Municipio in Napoli (South Italy). An energy sheet pile wall was built and equipped with fibre optic sensors system allowing the evaluation of strains and temperature distributions along the piles, during geothermal processes. Results on a single energy pile and measurements undertaken during the field experiment are presented highlighting the effects of temperature variations on the mechanical behaviour of the soil-structure system. From temperature measurements, it can be observed that, due to the excavation, there was a strong influence of the outside air temperature. Despite measurement uncertainties and some data gaps resulting from cut cables, the data presented makes a contribution to improving the available monitored case studies in the literature on energy structures.
\end{abstract}

\section{Introduction}

Over the years, numerous energy piles have been built in various structures and buildings and some as test piles. The installed thermo-active elements provide additional insight into the geotechnical and energy performance of energy piles under coupled mechanical and thermal loading. The pioneering projects on energy piles were reported by Brandl [1] studying the effect of temperature on energy pile bearing capacity. Later on, the influence of thermal constraint and cyclic temperature response energy pile mechanical behaviour were investigated by Laloui et al. [2], Amis et al. [3] and Bourne-Webb et al. [4] respectively. Using the above mentioned studies, Amatya et al. [5] developed a mechanism for the interaction between the energy pile and its surrounding soil under coupled thermo-mechanical load action. The effect of heating and cooling cycles on the radial thermal strain and shaft capacity were reported by Wang et al. [6] and Singh [7]. In addition, You et al. [8] investigated the effect heating modes on cement fly-ash gravel piles. Their findings discussed the axial stress distribution in the pile and creep rate of energy piles installed in stiff high plasticity clays due to associated effect of temperature increase. Furthermore, the influence of coupled thermo-mechanical load on the load redistribution, axial strain changes and induced vertical displacements in an energy pile were reported by Akrouch et al. [9], McCartney and Murphy [10] and Santiago et al. [11] respectively. Experimental results on complex energy geo-structure, as the one proposed in this study, are uncommon. The irregular geometry of the structure and the influence of high air temperature during geothermal operation make such experimental campaign a unique case study, if compared with other projects from the literature. The aim of this work is to describe the experimental set-up on one energy pile within a sheet pile wall built in Napoli $[12,13]$ and to analyse results, evaluating its performances in the investigated area during and after the geothermal operations.

\section{The experimental campaign}

"Piazza Municipio" is the name of a huge underground station which connects two lines of Napoli underground: Line 6, that flows parallel to the seaside, and Line 1, that connects the Vomero Hill (North part of the city) with the Railway Station. The construction activities in Piazza Municipio are still in progress to complete the connection between those lines. The involved natural deposits are the Yellow Tuff and the pozzolanas, deposited about 12000 years ago during the second phase of volcanic activity. Due to the good mechanical properties of the tuff, it was possible to excavate in a densely built environment to realize the station without significantly affecting any existing structures and infrastructures, even if the excavation level is well below the groundwater table.

A sheet pile wall was built to support the excavation for the location of train platform. Six of the forty-five bored pile foundations, installed as part of the pile wall, were converted into energy piles (EP) to exchange heat

\footnotetext{
* Corresponding author: marianna.adinolfi@cmcc.it
} 
with ground. Figure 1a summarizes the basic features of the set-up. The plan provides information of the investigated area and locate the six energy piles (black filled circles) within the sheet pile wall. The train platform of the original project is at $11.30 \mathrm{~m}$ below the ground level and, to support the excavation of around 6 $\mathrm{m}$ to locate the platform, the total length of piles is equal to $11.40 \mathrm{~m}$. A reinforced concrete slab, with height ranging from 0.80 to $0.40 \mathrm{~m}$, overlies the sheet pile wall. Although the instrumented piles during the heating test activities were three, this paper shows the results of the campaign related to one of them, the energy pile named EP2 (Fig.1a). The section in Figure 1b shows the layered conditions of the ground and the mechanical properties of concrete and soils [14]. Moreover, it indicates the excavation level, underlining that, at the time of heating activities, only the lower part of the wall is completely embedded into the ground, while the upper part of the wall is partially in touch with soils and partially exposed to the environmental conditions. The diameter of piles is $800 \mathrm{~mm}$ and inter-axis distance of $1.10 \mathrm{~m}$ (Figure 1c). The High Density Poly-Ethylene (HDPE) pipe (32 mm nominal diameter) was anchored to the pile reinforcing cage comprising by 12 bars of $24 \mathrm{~mm}$ in diameter. The reinforcement cage has been used also to support Optic Fibre Sensors (OFS), for strain and temperature measurements.

The campaign consisted in two main phases. The set-up phase started in December, 2015 with installation of the geothermal probes attached to the inner part of the reinforcement cage before the concrete casting. An arrangement of the instrumentation system, consisting mainly in OFS cables, was also installed. Once the set of authorisations for the tests were provided, and compatibly with all the other activities of the construction site, the second phase started in July, 2016 with thermal response test (TRT) carried out on EP2. TRT test provides assessment of the heat exchange response of the foundation, and, combined with the monitoring system, allowed to control the thermomechanical strains and induced temperature exchanges.

\subsection{The set-up}

The EP2 was bored and equipped with heat exchangers and optical fibre sensors cable. Figure 2 shows the installation of heat exchanger in EP2 with spiral pipes with a pitch between the turns of $0.70 \mathrm{~m}$. During the experimental set-up phase, measurements were made of strains and temperature by means of OFS cables anchored to the reinforcing cage (Figure 3). Two methods of installation: one with the cables anchored continuously along the length of the reinforcement cage at regular steps and one with the cable strung between the top and bottom of the cage. The former method concerns OFS for strain measurements. The three fibres were installed at 120 degree spacing along the pile circumference. The fourth optical cable, instead, was strung along the pile for temperature measurements.

OFS system has the advantage to provide continuous distributed measurements by means of a relatively cheap, but effective monitoring system with the advantages of small size, low weight, corrosion resistance, geometrical
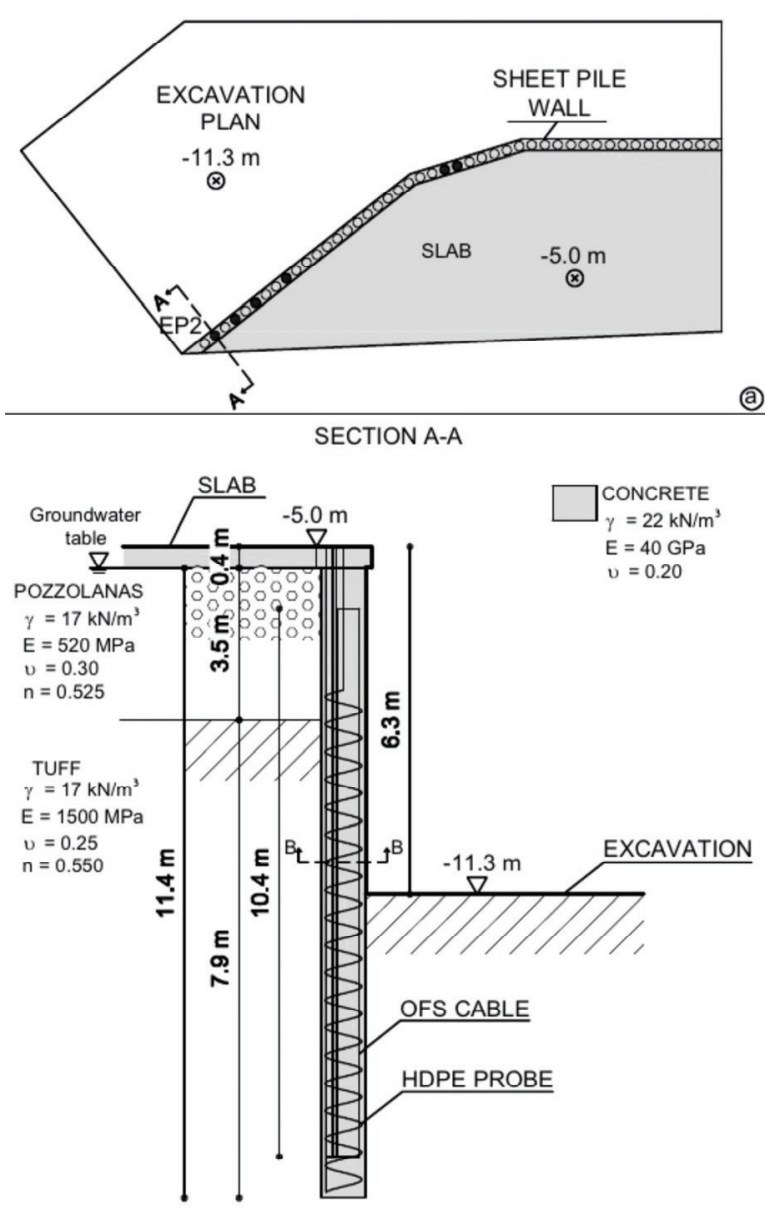

(1)

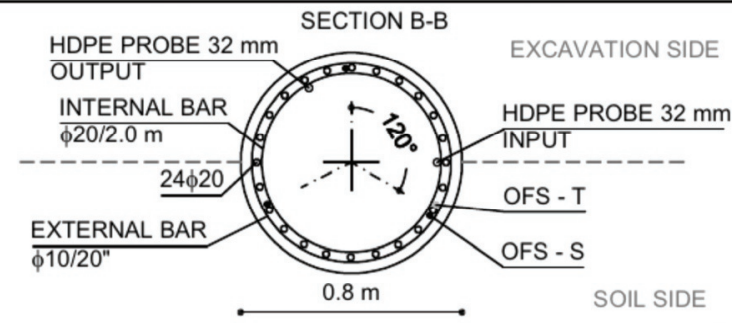

Fig. 1. The experimental set-up.

flexibility, and inherent immunity to electromagnetic interference. OFS provide accurate measurements but require a large dedicated reading unit and a computer to operate it. Indeed, the monitoring system was made up by an optoelectronic reading unit, including all the electronic and optical components and cables. 


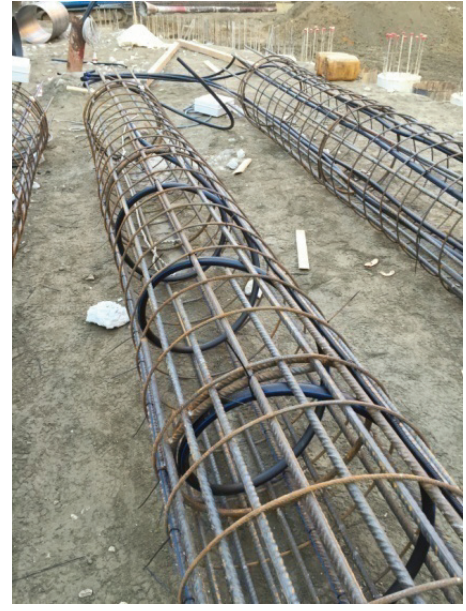

Fig. 2. The installed heat exchanger in EP2.
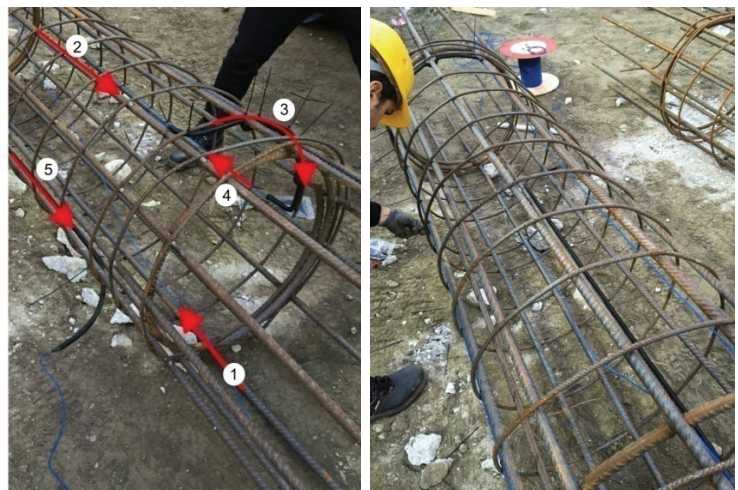

Fig. 3. The OFS installation: (a) OFS cable route, (b) anchored OFS (blu cables in the picture) and strung cable (black one).

\subsection{The thermal response test}

TRT allows to evaluate the heat exchange of the fluid entering and exiting the probes-equipped foundations. The heating manifold system used during the thermal response test is presented in Figure 4. The temperatures during heat pump operation (approximately 100 hours) were monitored using pipe-plug thermocouples installed in the inlet and outlet ports of the manifold, and records of the fluid outflow and return temperatures, simultaneously provided by a data logger. Thermal load control was given by manual switching of the heat pump to have the maximum heating outputs on each tested pile. The heating manifold system was supplied by electrical power and contains heating elements in contact with the circulating fluid that allow injecting a heat rate of $1 \mathrm{~kW}$. A pump was used to fill the tubes and get the system pressure. A manometer allowed a detailed water tightness check of absorber pipes. Four pipe-plug thermocouples were installed in the plumbing to record inlet and outlet fluid flow and returned temperatures. Moreover, a thermistor was installed on the heat pump to record the data of the outside air temperature in the surrounding of the tested piles. Thermal load control was given by manual switching of the heater. The data logger was located into the general control panel and connected to a battery. Fluid temperature measurements were recorded every five minutes using it, to capture the operations of heater and energy foundations. Moreover, the heating manifold system was able to monitor the variables used during the thermal response test: inlet and outlet fluid temperatures, inlet and outlet fluid pressures, flow rate and electrical consumption of the module. The duration for each test, carried out using a heat flow rate of $1 \mathrm{~kW}$, was of 100 hours, during which the pile was heated continuously. The last phase consisted in ending the test and, disconnect the equipment and the data logger. The absorber pipes were disconnected and all valves are closed for transport.

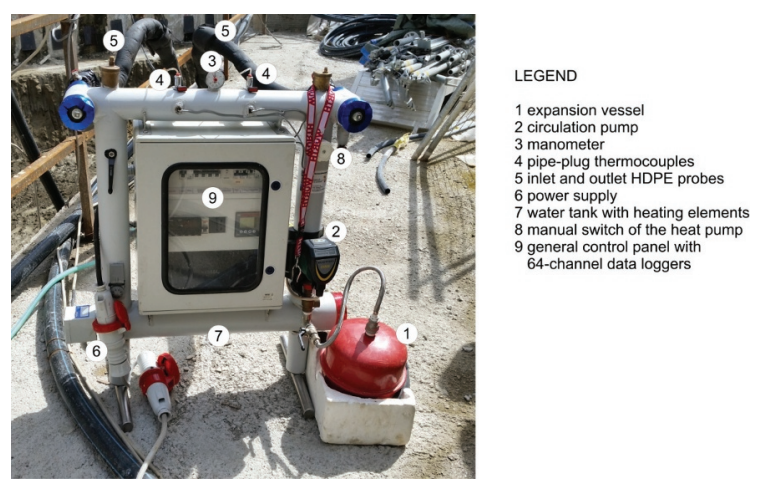

Fig. 4. The TRT equipment.

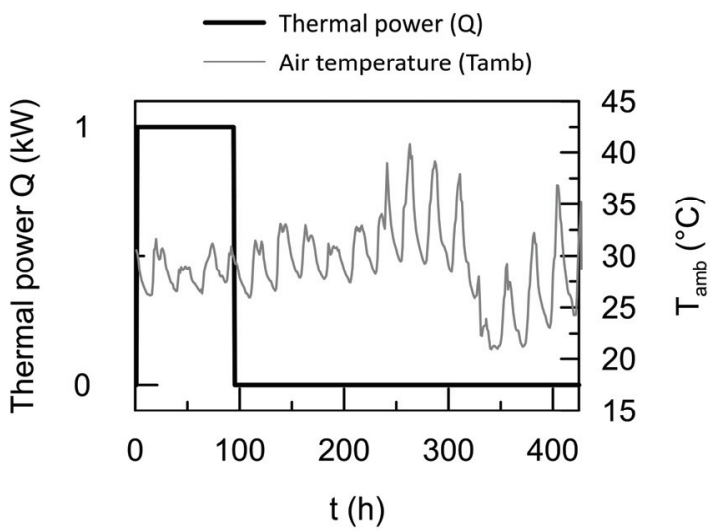

Fig. 5. The Heat flow rate $\mathrm{Q}(\mathrm{kW})$ and air temperature $T_{a m b}$ $\left({ }^{\circ} \mathrm{C}\right)$ versus time during TRT on EP2.

The described framework was used for TRT on EP2. The inlet temperature range applied during the thermal test period $\left(26^{\circ} \mathrm{C}\right.$ to $\left.37^{\circ} \mathrm{C}\right)$ was developed at the maximum outputs for the $1 \mathrm{~kW}$ heat pump used. The heat exchange fluid used in the TRT was water. The inlet and outlet fluid temperatures during TRT probes are not proposed in this study. An overall time-lapse of 425 hours was chosen for monitoring activities on EP2 while it was heated for the first 100 hours during TRT activities, as the time history in Figure 5. The air temperature recorded by the thermistor was also plotted in Figure 5. 


\section{Results of monitoring}

The experimental campaign on the energy piles of the retaining wall in Piazza Municipio was performed without any mechanical load applied (with the exception of the self-weight of the pile and of the slab) on the energy geo-structure neither influencing construction site activities. The reference measurement took place some hours before the heating of the first pile (close to EP2) at $\mathrm{t}=0 \mathrm{~h}$. Therefore, the so-called baseline reading, neglects the influence of previous activities on the sheet pile (i.e works for the excavation). It means that the behaviour of the structure presented in the following, is observed when only geothermal load acts (heating induced during TRT). Due to warm air temperatures on the part of the pile exposed to the excavation (Fig.5), the outside air temperature is to be considered as further thermal load. The recorded data during the monitoring cover a timeframe of 425 hours: gaps in between 90 and 120 hours, and 171 and 315 hours are due to accidental cuts in OFS cables. Nonetheless, the trends in the data are clear despite these gaps.

Results from OFS monitoring in terms of temperature, temperature and strain variations along EP2 are proposed in Figures 6 and 7, respectively. The variations are assessed as the difference between the profile at each time-step and the one at $\mathrm{t}=0 \mathrm{~h}$ (baseline reading). The horizontal dotted line represents the excavation plan, i.e. the portion of the pile above the excavation plan was exposed to the air temperature whereas the one below was completely enclosed by soils.

\subsection{Thermal behaviour of EP2}

A single OFS was used to monitor temperatures within the reinforced concrete foundation EP2 with a subhourly temporal resolution. Figure $6 \mathrm{a}$ and $6 \mathrm{~b}$ show temperature profiles and Figure $6 \mathrm{c}$ and $6 \mathrm{~d}$ show temperature variation profiles. The thermal behaviours of EP2 during and after geothermal activity, are respectively proposed in Figures $6 \mathrm{a} / \mathrm{c}$ and $6 \mathrm{~b} / \mathrm{d}$.

The profiles are generally decreasing with depth and the initial one is taken at $\mathrm{t}=0$ (Fig. 6a) along EP2 with temperature ranging from $18^{\circ} \mathrm{C}$ (pile toe) to $32^{\circ} \mathrm{C}$ (upper part) and the mean value is $27.5^{\circ} \mathrm{C}$. Once the TRT begins, the effect of heat injection in the temperature profiles is clear with a uniform increase at each subsequent time-step. At the end of TRT $(\mathrm{t}=90 \mathrm{~h})$, temperature reaches its peak of $45^{\circ} \mathrm{C}$ in the upper meters as at the pile toe is at $30^{\circ} \mathrm{C}$. The mean value is $37^{\circ} \mathrm{C}$. Figure $6 \mathrm{~b}$ proposes the temperature profiles after geothermal activities $(\mathrm{t}>100 \mathrm{~h})$. The profiles corresponding to time-steps between $121 \mathrm{~h}$ and $171 \mathrm{~h}$ show that temperatures are constantly decreasing, (i.e. both in the exposed and embedded part of the pile). At $\mathrm{t}=171 \mathrm{~h}$ the mean value of temperature along pile is $29.8^{\circ} \mathrm{C}$. Profiles corresponding to time-steps from $315 \mathrm{~h}$ till the end, show that temperature is decreasing only in the exposed part of pile (ranging from $30.6^{\circ} \mathrm{C}$ to $\left.28.2^{\circ} \mathrm{C}\right)$, while remains constant $\left(\mathrm{T}=26^{\circ} \mathrm{C}\right)$ in the embedded part. This behaviour highlights that: $(i)$ the effects of TRT act on EP2 until $171 \mathrm{~h}$ while disappear at $315 \mathrm{~h}$; (ii) the exposed part of EP2 is strongly influenced by outside air temperature impeding the heat transfer.
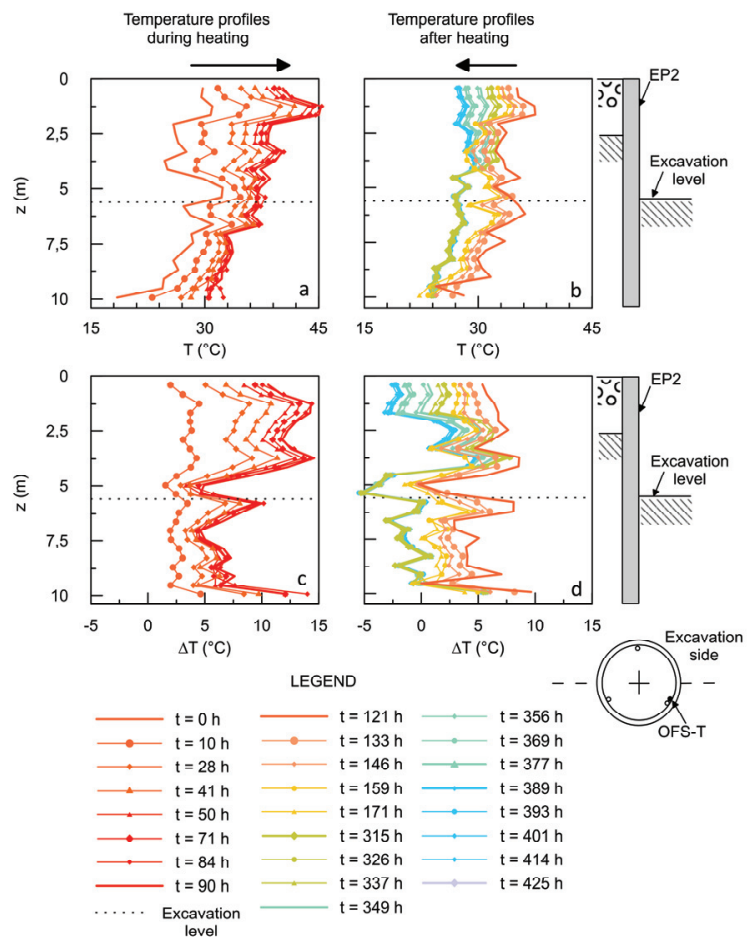

Fig. 6. Temperature and temperature variation profiles in EP2 during the heating induced by TRT and after heating.

The thermal evolution of the pile in terms of temperature change with respect to the baseline reading is proposed in Figure $6 \mathrm{c}$ and $6 \mathrm{~d}$. Generally, a notable variation in the values of temperature variation with depth is observed. Rui et al. [15] suggest that fluctuations in temperature measurements by OFS are usual and indicate anomalies in the pile integrity (i.e. changes in the pile geometry with pile depth due to concrete hydration temperature and small changes in concrete cover). Moreover, such result is also associated with the markedly fluctuating values of initial temperature at the considered site, as compared to the uniform values of temperature induced by thermal loading of EP2. At $\mathrm{t}=90 \mathrm{~h}$ (Fig. 6c), the geothermal operation and the field environmental conditions involved average temperature variations along the pile of $\Delta T=9{ }^{\circ} \mathrm{C}$ (with a maximum of $14.5^{\circ} \mathrm{C}$ ). The profiles corresponding to time-steps from $121 \mathrm{~h}$ and $171 \mathrm{~h}$ (Fig. 6d) show that temperature variations are decreasing both in the exposed and embedded part of the pile. The mean temperature variations at $\mathrm{t}=171 \mathrm{~h}$ is $\Delta T=2.2{ }^{\circ} \mathrm{C}$. From $315 \mathrm{~h}$ till the end, temperature variations decrease only in the exposed part $\left(\Delta T\right.$ goes from $3^{\circ} \mathrm{C}$ to $\left.0^{\circ} \mathrm{C}\right)$. The embedded part shows at the end of the campaign $(\mathrm{t}=425 \mathrm{~h})$ a negative mean temperature variation $(\Delta T=-$ $0.5^{\circ} \mathrm{C}$ ) referring to the beginning of the test. It is worth to note that singular points are observed in all profiles close to: $(i)$ the excavation plan and (ii) the plan in between different soil layers (pozzolanas and tuff). 


\subsection{Strain response of EP2}

The other three OFS, anchored to the reinforcing cage of the pile, were used to monitor the strains along the foundation on a sub- hourly temporal resolution. Figure 7 shows thermally induced strain variations along EP2 (contractive strains are considered as negative). The thermally induced strain changes are evaluated with respect to the baseline reading. As for temperature, the behaviour of pile is captured during (Fig. $7 \mathrm{a} / \mathrm{c} / \mathrm{e}$ ) and after (Fig. 7b/d/f) TRT. Moreover, the couple of Figures $7 \mathrm{a}-\mathrm{b}$ relates to OFS close to the one that measures temperature (see the section on the side). Figures $7 \mathrm{c}-\mathrm{d}$ relate to the OFS mainly exposed to the excavation as Figures $7 \mathrm{e}-\mathrm{f}$ refer to the OFS at $120^{\circ}$ from the previous one.

Generally, a notable variation in the values of thermally induced vertical strain variation with depth is observed. This result is associated with the interplay between the markedly fluctuating values of temperature variations with depth and the thermally induced vertical strains.

Once the TRT begins (Fig. 7a), the effect of heat injection is clear and the pile results in an almost uniform and increasing expansion in subsequent timesteps. At $\mathrm{t}=90 \mathrm{~h}$, the mean value is $\Delta \varepsilon z=80 \mu \varepsilon$. At this stage, a greater expansion is observed if compared with the profiles of temperature variation responsible for this strain change. This result is partly attributed to the greater average temperature variation observed in the exposed portion of the energy pile.

The profiles corresponding to time-steps in $121 \mathrm{~h}$ and $171 \mathrm{~h}$ (Fig. $7 \mathrm{~b}$ ), subsequent of the geothermal operation, show limited average vertical strain variations, but still fluctuating with the development of both expansive and contractive strains. The mean value at the end of the campaign ( $\mathrm{t}=425 \mathrm{~h})$ is around $\Delta \varepsilon z=13$ $\mu \varepsilon$. Singular points in thermal induced strain variations, close to the change in soil layers plan and to the excavation plan, are also observed.

Such points are also marked in Figure $7 \mathrm{c}$ also if the trend of profile is anyway to expansion, due to geothermal operation. At $\mathrm{t}=90 \mathrm{~h}$, the mean value is $\Delta \varepsilon Z$ $=58 \mu \varepsilon$. In Figure $7 \mathrm{~d}$, a contractive behaviour of the pile is observed at all stages (especially in the upper part of the pile), in agreement with temperature variation profiles (Fig. $6 \mathrm{c}$ and d). The mean value at the end of the campaign $(\mathrm{t}=425 \mathrm{~h})$ is around $\Delta \varepsilon z=-25 \mu \varepsilon$. This behaviour is due to the OFS position that is closer to the excavation than others. Figures $7 \mathrm{e}$ and $7 \mathrm{f}$ show the profiles of thermally induced strain variations at the OFS enclose into soil (as the one of Figure $7 a$ and $7 b$ ). Expansive behaviour is performed during geothermal operation (Fig.7e). At $\mathrm{t}=90 \mathrm{~h}$, the mean value is $\Delta \varepsilon Z=110 \mu \varepsilon$. Although markedly fluctuating values of strain (Fig.7f) occurred after the geothermal operation with the development of both expansive and contractive strains, the induced thermal strain variations disappear at the end of the experimental campaign. Indeed, the mean value at the end of the campaign $(\mathrm{t}=425 \mathrm{~h})$ is around $\Delta \varepsilon Z=10 \mu \varepsilon$.
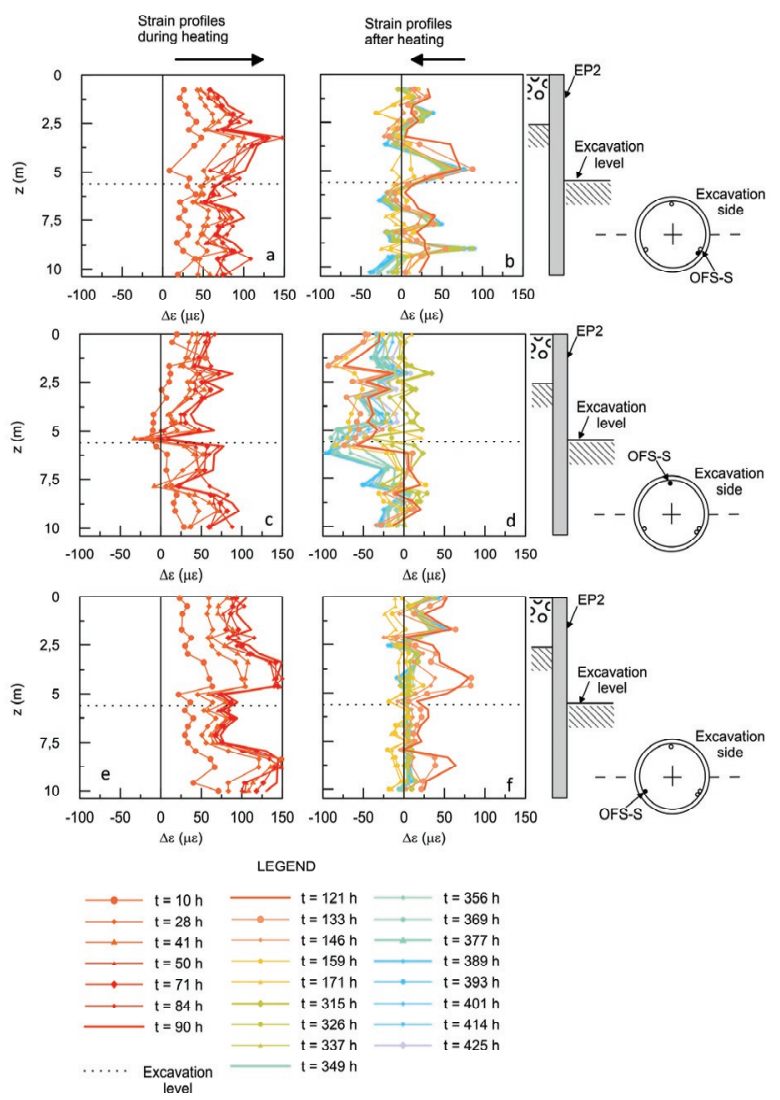

Fig. 7. Strain variation profiles in EP2 during the heating induced by TRT and after heating.

\section{Conclusions}

The work aims at describing the experimental campaign on an energy pile within a sheet pile wall built in Napoli and providing results during and after the geothermal operations. Data collected from OFS allowed to assess the thermal effects on the mechanical behaviour of the pile in terms of strain variations.

- At the beginning of the experimental campaign, the initial temperature of the reinforced concrete was markedly fluctuating and ranged from $18^{\circ} \mathrm{C}$ to $32^{\circ} \mathrm{C}$. During geothermal operation the temperature into pile increases relatively uniform with depth reaching a maximum increase at $\mathrm{t}=90 \mathrm{~h}$ of around $\Delta T=9^{\circ} \mathrm{C}$.

- After geothermal operation, temperature profiles vary only in the exposed part of EP2, due to the influence of the outside air temperature. It also means that the temperatures return to the baseline conditions more quickly in the embedded section, suggesting that the heat transfer is impeded in the exposed section of the wall by the outside temperature. The temperature variations of the embedded part remain constant performing negative mean value $\left(\Delta T=-0.5^{\circ} \mathrm{C}\right)$ referring to the beginning of the test.

- A notable variation in the values of temperature variation with depth is observed at all time-steps. This result is associated with the markedly 
fluctuating values of initial temperature, the uniform values of temperature induced by geothermal activities, the complex geometry of the energy sheet pile wall and boundary conditions of the considered site. Indeed singular points are observed close to the excavation plan and at the change of thermomechanical properties of the different involved soils (pozzolanas and tuff).

- A notable variation in the values of thermally induced vertical strain variation with depth is observed at all time-steps. This result is in agreement with temperature variation that are responsible for this strain change.

- During geothermal operation, the pile performs an expansive behaviour. At $\mathrm{t}=90 \mathrm{~h}$, the mean value of thermally induced vertical strain variation along EP2 is around $\Delta \varepsilon z=80 \mu \varepsilon$ and $110 \mu \varepsilon$ along the OFS enclosed in soils, as $\Delta \varepsilon Z=58 \mu \varepsilon$ along the OFS close to the excavation.

- Markedly fluctuating values of strain occurred along the OFS enclosed in soils after the geothermal operation, with the development of both expansive and contractive strains. The induced thermal strain variations disappear at the end of the experimental campaign (i.e. value of thermally induced vertical strain variation of around $\Delta \varepsilon z=10 \mu \varepsilon$ at $\mathrm{t}=425 \mathrm{~h}$ ).

- A contractive behaviour of the pile is observed at all stages after geothermal operation (especially in the upper part of the pile), along the OFS close to the excavation (i.e. mean value at $\mathrm{t}=425 \mathrm{~h}$ of around $\Delta \varepsilon z$ $=-25 \mu \varepsilon)$. This is in agreement with temperature variation profiles and highlights the strong influence of the environmental conditions on the results of the proposed experimental campaign.

Nevertheless, the thermal impacts due to double thermal loads (geothermal operation and high air temperature) on the mechanical response of the pile would not likely lead to significant structural problems. The interplay between thermal loads and the complex geometry of an energy pile within a sheet pile wall affect the experimental results and make such experimental campaign a unique case study, if compared with other projects from the literature.

The authors gratefully acknowledge the financial support of GeoGrid project PON03PE_00171, the head director of the underground construction site and LaTEC research group from University of Napoli Parthenope for the technical support during the campaign.

\section{References}

1. H. Brandl. Energy foundations and other thermoactive ground structures. Géotech 56, 81-122 (2006)

2. L. Laloui, M. Nuth, L. Vulliet. Experimental and numerical investigations of the behaviour of a heat exchanger pile. Int $J$ Numer Anal Methods Geomech 30, 763-81 (2006)

3. T. Amis, P.J. Bourne-Webb, C. Davidson, B.L. Amatya, K. Soga. The effects of heating and cooling energy piles under working load at Lambeth
College. In: Proc 33rd Annu 11th Int Conf Deep Found 10 (2008)

4. P.J. Bourne-Webb, B. Amatya, K. Soga, T. Amis, C. Davidson, P. Payne. Energy pile test at Lambeth College, London: geotechnical and thermodynamic aspects of pile response to heat cycles. Géotechnique59, 237-48 (2009)

5. B.L. Amatya, K. Soga, P.J. Bourne-Webb, T. Amis, L. Laloui. Thermo-mechanical behaviour of energy piles. Géotechnique 62, 503-19 (2012)

6. B. Wang, C. Haberfield, S. Baycan. Field investigation of a geothermal energy pile: Initial observations. Geotech-Fr Org 3415-8 (2013)

7. R.M. Singh, A. Bouazza, B. Wang. Near-field ground thermal response to heating of a geothermal energy pile: Observations from a field test. Soils Found 55, 1412-26 (2015)

8. S. You, X. Cheng, H. Guo, Z. Yao. In-situ experimental study of heat exchange capacity of CFG pile geothermal exchangers. Energy Build 79, 23-31 (2014)

9. G.A. Akrouch, M. Sánchez, J.L. Briaud. An experimental, analytical and numerical study on the thermal efficiency of energy piles in unsaturated soils. Comput Geotech 71, 207-20 (2016)

10. J.S. McCartney, K.D. Murphy. Strain distributions in full-scale energy foundations. J Deep Found Inst 6, 26-38 (2012)

11. C. De Santiago, F.P. De Santayana, M. De Groot, J. Urchueguía, B. Badenes, T. Magraner, et al. Thermo-mechanical behavior of a thermo-active precast pile. Bulg Chem Commun 48, 41-54 (2016)

12. M. Adinolfi, A. Mauro, R.M.S. Maiorano, N. Massarotti,, S. Aversa. Thermo-mechanical behaviour of energy pile in underground railway construction site. In: Proc 1st Int. Conf. on Energy Geotechnics, 83 (2016)

13. M. Adinolfi, A. F. Rotta Loria, L. Laloui, S. Aversa. Experimental and numerical investigation of the thermo-mechanical behavior of an energy sheet pile wall. Geomechanics for Energy and the Environment (accepted) (2020) https://doi.org/10.1016/j.gete.2020.100208

14. M. Adinolfi, R. M. S. Maiorano, A. Mauro, N. Massarotti, S. Aversa. On the influence of thermal cycles on the yearly performance of an energy pile. Geomechanics for Energy and the Environment 16, 32-44 (2018)

15. Rui, Y., Kechavarzi, C., O’Leary, F., Barker, C., Nicholson, D., \& Soga, K. (2017). Integrity testing of pile cover using distributed fibre optic sensing. Sensors, 17(12), 2949. 